\title{
THE CAUSES OF MINING INDUCED GROUND STEPS OCCURENCE - CASE STUDY FROM UPPER SILESIA IN POLAND
}

\author{
Piotr STRZAŁKOWSKI* and Roman ŚCIGAŁA
}

Silesian University of Technology, ul. Akademicka 2a, 44-100 Gliwice, Poland

*Corresponding author's e-mail: piotr.strzalkowski@polsl.pl

\begin{tabular}{l} 
ARTICLE INFO \\
\hline Article history: \\
Received 19 January 2017 \\
Accepted 26 April 2017 \\
Available online 11 May 2017 \\
\hline
\end{tabular}

Keywords:

Post-mining discontinuous deformations Ground steps

Predictions of post-mining deformations

\begin{abstract}
The case study of a ground steps creation due to underground mining in Upper Silesia Basin, where for many years was conducted intensive hard coal extraction has been presented in this paper. This type of linear discontinuous deformations is considered as an important threat to the surface building constructions and elements of underground technical infrastructure.

This threat is even more important, that presently still we do not have methods for predictions of such phenomena, and protection of building constructions against such damages is difficult, if not impossible. On the basis of the analyzes results shown in the paper, the following factors were pointed, that favor the formation of mining-induced ground steps: the presence of fault outcrops in the vicinity of extraction fields, multiple extraction in several coal seams led to the same border and large values of tensile horizontal strain.
\end{abstract}

\section{INTRODUCTION}

In the conditions of Upper Silesian Coal Basin, a significant part of mining extraction has been carried out under the largest Polish urban and industrial agglomeration since the XVIII century. Presently, due to changes in Polish national economy, the intensity of extraction is less than in the $70 \mathrm{~s}$ and $80 \mathrm{~s}$ of the XX century, but high degree of rock mass fracturing due to mining works still creates important safety problems to land surface.

Generally it can be said, that the impact of underground coal mining on the environment covers a wide range of factors. Among them, the most important are continuous and discontinuous terrain deformations. Continuous deformations, manifesting in the shape of subsidence troughs and their derivatives, accompany mining extraction independently from mining-geological conditions. They can be predicted with sufficient for practice quality with using wide range of methods. The most wide spread used in Polish hard coal mining industry in this field is the Budryk-Knothe theory (Knothe, 1953). Description of this method as well as others used in different countries reader can find among others in (Kratsch, 1983; Peng 2008; Strzałkowski, 2010).

Discontinuous deformations can be divided into two general types: surface-type with typical representation by sinkholes of various shapes, and linear-type represented by cracks, gaps and ground steps. Discontinuous deformations are more difficult to predict, especially taking into account random nature of such processes. So for the surface-type deformations, majority of forecasting methods is limited to determination of the probability of sinkhole arising (Chudek et al., 1988). Concerning prediction of linear-type discontinuous deformations, up to present day we still do not have complete solution to this problem. Some cases of such deformations arising were analyzed in works (Kratzsch, 1983; Li et al., 2004; Kotyrba and Kowalski, 2009; Strzałkowski and Ścigała, 2008; Woo et al., 2013). In those works the most important sources of ground steps and cracks creation were pointed out as: tectonic faults activation and extraction in several coal seams to the same border line (e.g. the border of protective pillars or border of mining area).

In the work (Strzałkowski, 2014) there was an assumption presented which states, that the main cause of linear discontinuous deformations creation is the presence of high tensile horizontal strain due to intensive underground mining works. This assumption has its confirmation in practical findings, for example work (Kaizong et al., 2016) presents the occurrence of numerous linear deformations outside the area of deposit extracted to a large thickness, in the zone of tensile horizontal strain. In one of the latest Polish works devoted to creation of linear discontinuous deformations, conditions of their arising in the Lublin Coal Basin were presented, where relatively recently mining extraction was led (Malinowska and Hejmanowski, 2016). In this work, authors pointed 


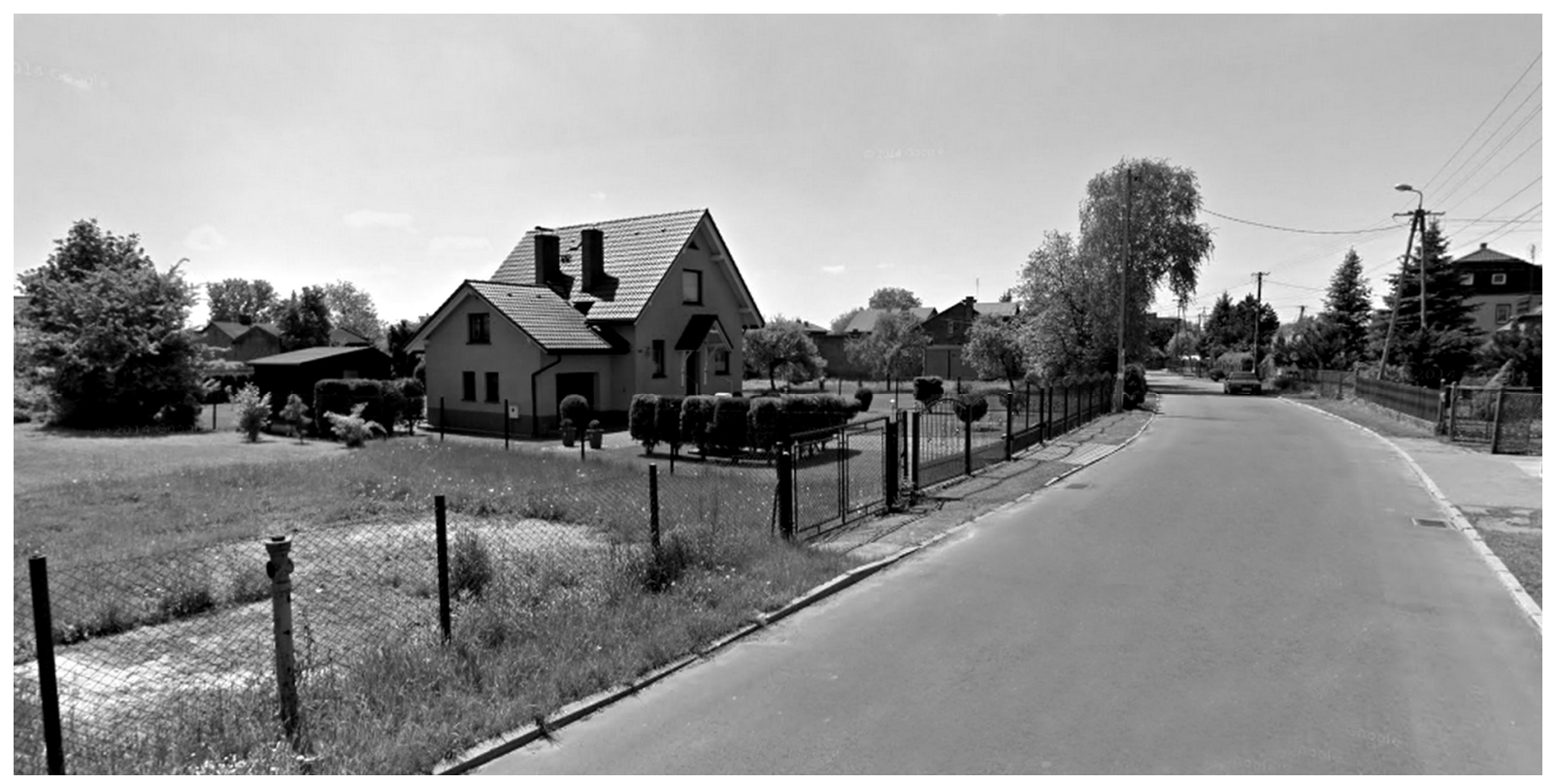

Fig. 1 Typical view of the land use in the study area.

out the following factors influencing the creation of linear-type discontinuous deformations:

- the presence of horizontal tensile strain with values exceeding $+2.5 \mathrm{~mm} / \mathrm{m}$,

- participation of clay rocks in overburden and marl rocks in coal-bearing series,

- lack of impact from previous extraction.

There was a test proposed in this work to check, if some mining conditions may lead to creation of such deformations. The test bases on the answers to the following questions:

1. Is the ground surface influenced by earlier extraction?

2. If so, was the speed of extraction greater than $5 \mathrm{~m} /$ day?

3. Is the size of extracted field greater than $0.8 * \mathrm{r}$ ( $\mathrm{r}$ - radius of major influence range)?

According to the authors, if all answers to stated above questions are positive, one must be aware of high probability of linear-type deformation arising. The test concerns mining-geological conditions of Lublin Coal Basin in Poland.

As a part of this work, a case study of discontinuous linear-type deformation creation in Upper Silesia region has been presented. In the research area long-term intensive hard coal extraction was carried out in the past.

\section{THE CASE STUDY OF LINEAR DISCONTINUOUS DEFORMATIONS ARISING \\ 2.1. DESCRIPTION OF THE STUDY AREA}

The area of interest is located in the centre of Polish part of Upper Silesian Basin. The terrain morphology is not complicated, surface is generally flat with average height of $250 \mathrm{~m}$ above sea level.
Most of the study area is occupied by arable fields and grassland. As regarding land development, majority of buildings are single and two-storey family houses. Many local roads exist with asphalt surface. The are several building objects of greater cubature as: markets, school and church. The example of typical topography and land use in the study area is presented in Figure 1.

\subsection{LITHOLOGY AND STRATIGRAPHY}

On the basis of the borehole log sheet presented in Figure 2 it can be stated, that in the considered area, the rock mass consists of overburden and Carboniferous layers. Overburden creates Quaternary and Tertiary rocks with thickness of approximately $180 \mathrm{~m}$. Quaternary part with thickness of approximately $92 \mathrm{~m}$ consists mainly of sand and quick-sand layers. Tertiary layers are formed mainly with gray silts and partially red silts.

Below overburden layers, Carboniferous rocks exist, with upper part consisting of "orzeskie" layers. They are formed as: red and brown silt, shale, sandstone layers and coal seams 359, 361 existing below the depth of 400 meters. Below "orzeskie" layers, there are "rudzkie" layers with coal seams 401, 404 and 405 . The average dip angle varies in the range between $8^{\circ}$ and $15^{\circ}$, with south - west inclination.

\subsection{MINING EXTRACTION LED IN THE PAST}

In the considered area, very intensive extraction was carried out in the past - 34 longwall fields have been mined out since 1975. All extraction was led with caving, the depth was variable in the range $410-$ 960 meters. Coal seams in this area have inclination about $10^{\circ}-15^{\circ}$ in the south - west direction. More detailed data concerning the extraction is shown in Table 1. The sketch of extracted field location is shown in Figure 3. 

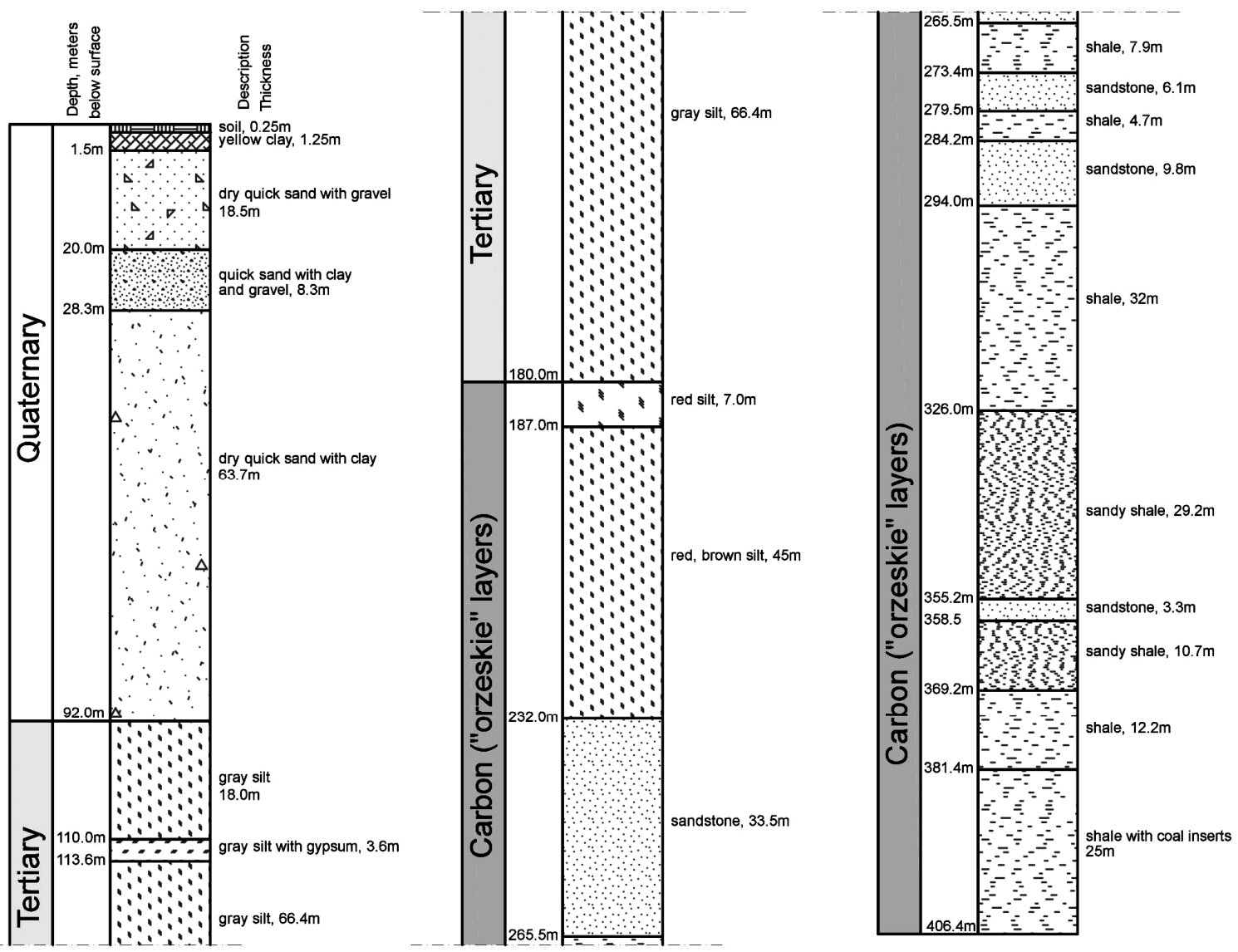

Fig. 2 The simplified borehole log presenting lithology and stratygraphy of the rock mass up to the depth of $400 \mathrm{~m}$.

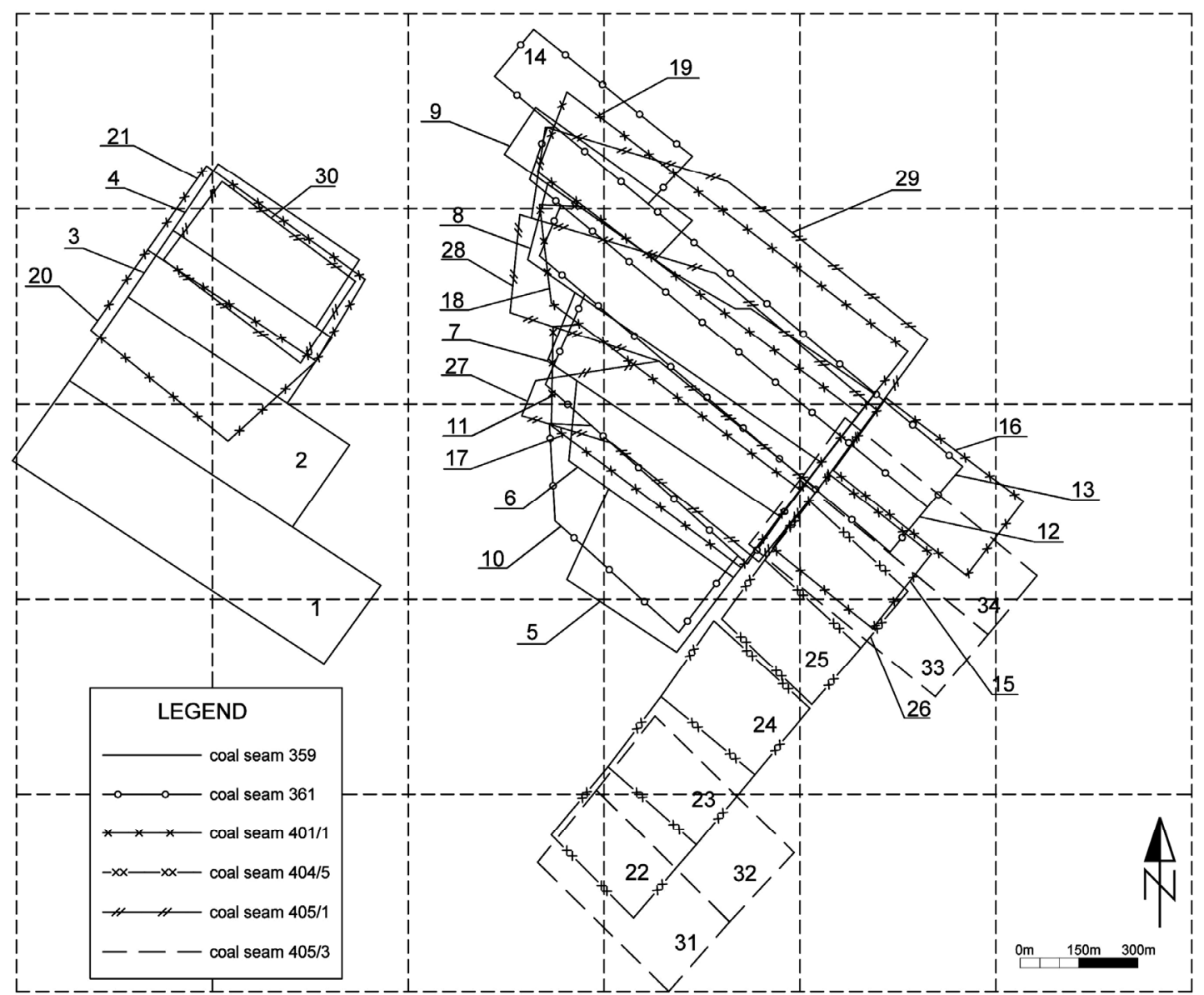

Fig. 3 The sketch of extracted fields location. 
Table 1 Basic mining-geological data concerning carried out extraction.

\begin{tabular}{|c|c|c|c|c|c|c|}
\hline Coal seam & Panel No & Start of extraction & End of extraction & $\begin{array}{c}\text { Extracted } \\
\text { thickness, } \\
{[\mathrm{m}]}\end{array}$ & $\begin{array}{c}\text { Angle of } \\
\text { dip, } \\
\text { [deg] }\end{array}$ & $\begin{array}{l}\text { Extraction } \\
\text { depth, }[\mathrm{m}]\end{array}$ \\
\hline 359 & 1 & 01-01-2002 & $31-12-2002$ & 2.00 & 10 & 695 \\
\hline 359 & 2 & 01-09-1998 & 31-12-1999 & 2.10 & 10 & 655 \\
\hline 359 & 3 & 01-01-1998 & 31-12-1998 & 1.95 & 10 & 600 \\
\hline 359 & 4 & 01-01-1997 & $31-12-1997$ & 2.00 & 10 & 550 \\
\hline 359 & 5 & 01-10-1995 & $30-03-1996$ & 1.75 & 12 & 630 \\
\hline 359 & 6 & 01-10-1992 & $30-06-1993$ & 1.80 & 14 & 575 \\
\hline 359 & 7 & 01-10-1987 & $30-04-1990$ & 1.90 & 18 & 530 \\
\hline 359 & 8 & 01-10-1987 & 01-12-1989 & 2.10 & 20 & 470 \\
\hline 359 & 9 & 01-01-1975 & $01-12-1975$ & 1.70 & 15 & 430 \\
\hline 361 & 10 & 01-07-1997 & 31-01-1998 & 1.90 & 10 & 630 \\
\hline 361 & 11 & 01-02-1995 & $31-12-1995$ & 1.70 & 15 & 565 \\
\hline 361 & 12 & 01-12-1990 & 01-12-1990 & 1.70 & 15 & 510 \\
\hline 361 & 13 & 01-11-1990 & $30-01-1992$ & 1.70 & 15 & 470 \\
\hline 361 & 14 & 01-01-1990 & $30-06-1990$ & 1.70 & 12 & 410 \\
\hline $401 / 1$ & 15 & 01-07-2008 & $31-12-2008$ & 2.00 & 10 & 910 \\
\hline $401 / 1$ & 16 & $01-02-2007$ & $30-09-2007$ & 2.00 & 10 & 845 \\
\hline $401 / 1$ & 17 & 01-02-1998 & 01-12-1998 & 2.60 & 13 & 625 \\
\hline $401 / 1$ & 18 & 01-05-1996 & $30-06-1997$ & 2.85 & 12 & 550 \\
\hline $401 / 1$ & 19 & 01-01-1995 & $31-12-1995$ & 2.70 & 12 & 490 \\
\hline $401 / 1$ & 20 & 01-01-1988 & $31-12-1988$ & 2.60 & 15 & 680 \\
\hline $401 / 1$ & 21 & 01-11-1989 & $31-12-1989$ & 2.60 & 15 & 610 \\
\hline $404 / 5$ & 22 & 01-11-1996 & 01-03-1997 & 1.90 & 10 & 935 \\
\hline $404 / 5$ & 23 & 01-04-1998 & $30-05-1998$ & 1.75 & 10 & 905 \\
\hline $404 / 5$ & 24 & 01-06-2000 & 01-09-2000 & 1.80 & 10 & 865 \\
\hline $404 / 5$ & 25 & 01-01-1980 & $30-06-1980$ & 1.80 & 10 & 825 \\
\hline $404 / 5$ & 26 & 01-01-1980 & $30-06-1980$ & 1.80 & 10 & 790 \\
\hline $405 / 1$ & 27 & 01-01-2006 & $30-09-2006$ & 2.60 & 10 & 790 \\
\hline $405 / 1$ & 28 & 01-10-2004 & $30-06-2005$ & 2.60 & 15 & 730 \\
\hline $405 / 1$ & 29 & 01-01-2002 & $01-12-2002$ & 2.70 & 15 & 700 \\
\hline $405 / 1$ & 30 & 01-01-2002 & $30-06-2002$ & 2.50 & 15 & 815 \\
\hline $405 / 3$ & 31 & 01-09-2001 & $31-12-2001$ & 3.50 & 10 & 995 \\
\hline $405 / 3$ & 32 & 01-06-2003 & $30-09-2003$ & 3.70 & 10 & 960 \\
\hline $405 / 3$ & 33 & 01-10-1995 & $30-06-1996$ & 3.70 & 10 & 830 \\
\hline $405 / 3$ & 34 & 01-02-1994 & 01-02-1995 & 3.70 & 10 & 780 \\
\hline
\end{tabular}

\subsection{TECTONICS}

In the study area tectonically disturbed zone exists. It was recognized by underground mining works during driving of local roadways crossing the zone. So the run of fault zone across the rock mass is known only partially. Fault zone creates a kind of rift valley, with faults on the east side throwing to the west with vertical drop of $8 \mathrm{~m}$ and $26 \mathrm{~m}$, and faults located in the west part throwing layers eastwards with height in the range $17 \mathrm{~m}-24 \mathrm{~m}$. Their outcrop lines on the top of Carboniferous layers run in approximately meridional direction. The course of most important faults outcrops is shown in Figures 5 and 6.

\subsection{THE CHARACTERISTICS OF DISCONTINUOUS DEFORMATIONS CREATED ON THE SURFACE}

In the considered area several ground steps were created as an effect of underground mining activity.
Steps with vertical drop between $6 \mathrm{~cm}$ and $20 \mathrm{~cm}$ ran approximately latitudinally, with slight variation depending on the extraction edges geometry and fault outcrops positions. More details are provided in the next part of the paper. Ground steps crossed local roads causing a lot of damages to road surface Figure 4. Location of created ground steps against extracted field location is presented in Figure 5.

\subsection{PERFORMED CALCULATIONS AND ANALYSIS OF THE RESULTS}

Due to lack of valuable geodetic measurements from the study area, calculations were performed aiming at evaluating the most probable subsidence and horizontal strain distribution in the vicinity of discontinuous deformations observed on the ground surface.

For evaluating the ground surface deformation state in the considered area, calculations were 


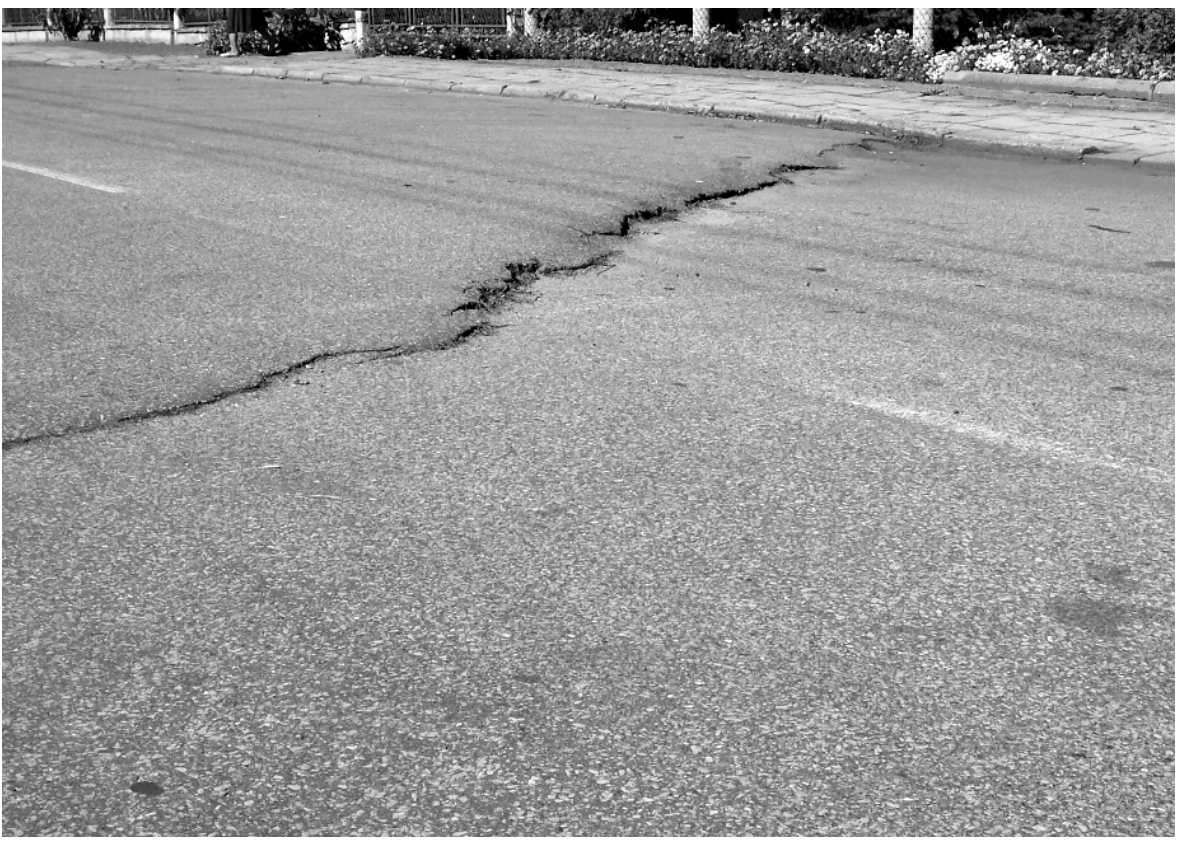

Fig. 4 One of the ground steps created on the road surface.

performed with using DEFK-Win software (Ścigała, 2008), which bases on the Budryk-Knothe theory (Knothe, 1953). Long-term experiences from Polish coal industry point, that this model characterizes good consistency with geodetic measurements results. For calculation purposes, the following values of parameters were used:

- the coefficient of roof control for extraction with caving: $\mathrm{a}=0.8$,

- the tangent of major influence range: $\operatorname{tg} \beta=2.0$,

- the coefficient of horizontal strain: $\mathrm{B}=0.32 \mathrm{r}$,

- the extraction boundary: $\mathrm{d}=0.0 \mathrm{~m}$.

Figure 5 shows the map of the total thickness of extracted deposit, along with contour lines of subsidence caused by considered extraction. As it can be seen from the map, maximum extracted thickness reaches the value of approximately $10 \mathrm{~m}$, while maximum subsidence amounts to $6.5 \mathrm{~m}$. Created on the surface discontinuous deformations in the shape of ground steps, shown on the map with red colour, are located outside the plan view of extracted panels, mainly close to extraction edges and fault outcrops (marked with blue lines in Figure 5).

The map of maximum horizontal strain is presented in Figure 6. Maximum horizontal strain $\varepsilon_{\max }$ was calculated as:

$\varepsilon_{\max }=\max \left(\left|\varepsilon_{1}\right|,\left|\varepsilon_{2}\right|\right)$

Tensile strain values (elongation) are shown as positive values, while the compressive (shortening) as negative ones. Additionally, vectors of principal strain $\varepsilon_{1}$ and $\varepsilon_{2}$ are drawn with black and gray lines respectively. These lines mark the magnitude and directions of $\varepsilon_{1} / \varepsilon_{2}$, while the dots at the end of lines indicate negative value of $\varepsilon_{1} / \varepsilon_{2}$ (compressive strain).

Comparing the course of ground steps with the distribution of horizontal strain and location of fault outcrops, it may be stated the following:

- In case of ground steps located in north-east part of considered area it may be assumed, that their direction nearly follows the contour lines of maximum tensile horizontal strain $\varepsilon_{\max }$ of value $+9 \mathrm{~mm} / \mathrm{m}$. The direction of principal strain $\varepsilon_{1}$ (tensile) in this zone (Fig. 6) is perpendicular to ground step line, which additionally proves the influence of local strain state on the creation of this deformation.

- Ground steps in the central and south-east part of considered area were created in the zone of faults outcrops on the roof of carboniferous layers. Horizontal strain $\varepsilon_{\max }$ reaches here the value of $+6 \mathrm{~mm} / \mathrm{m}$, so this is the same value of strain as in north-west part, where no ground steps occurred. The direction of principle strain $\varepsilon_{1}$ (tension) in this zone (Fig. 6) is perpendicular to ground step line too. The directions of steps throw are different and it is hard to tie them with directions of tectonic faults throw. So for this area it may be assumed, that the sum of factors: large values of tensile strain in certain directions, existence of fault outcrops and covering of old extraction edges in several coal seams were causes of deformations arising.

- In south-west part of considered area, ground steps were formed in the vicinity of tectonic faults outcrop. The number of steps here is less than that in the central part. It has to be pointed, that calculated maximum horizontal strain is here of 


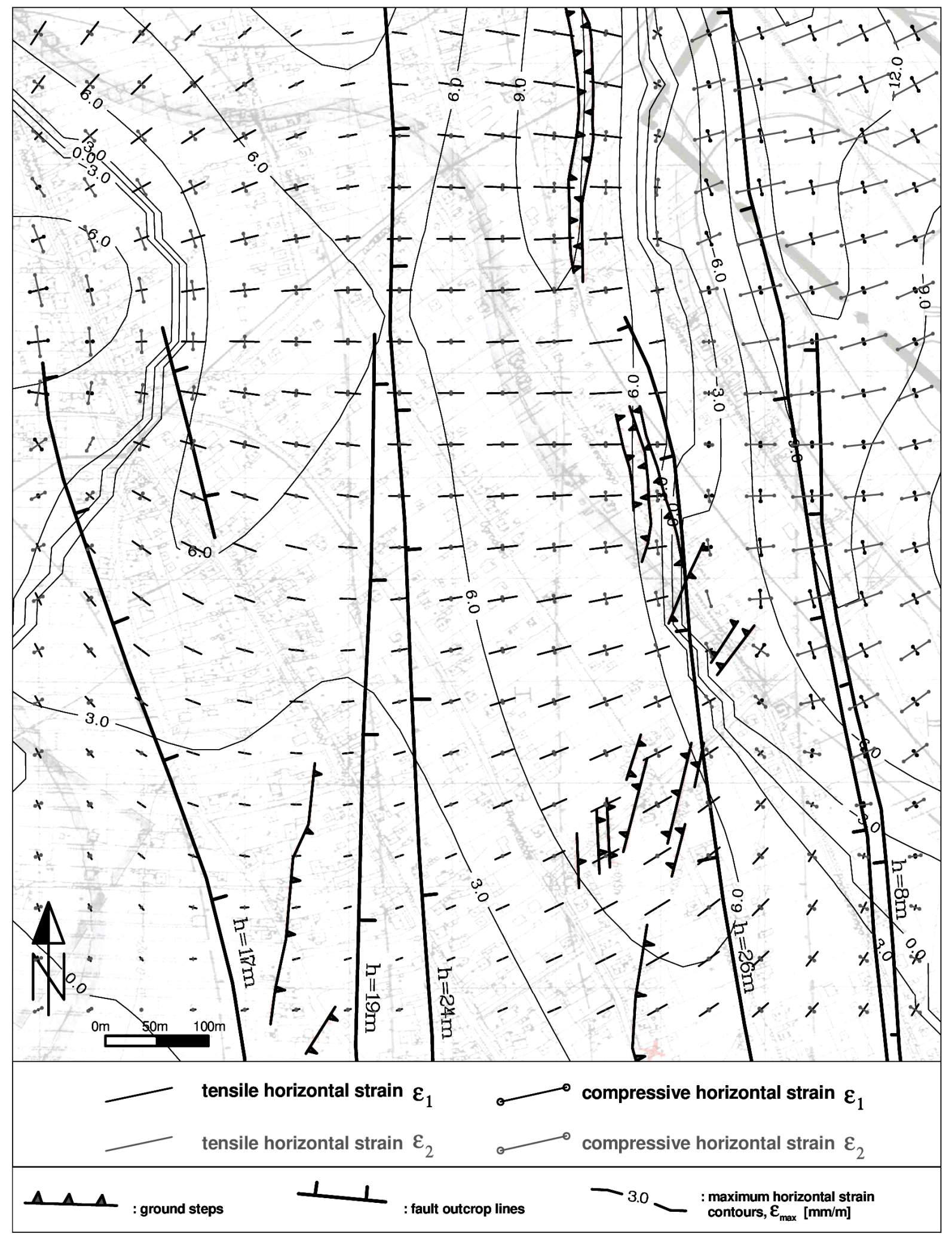

Fig. 6 The map of horizontal strain distribution. 
definitely lower value - at the level of $+3 \mathrm{~mm} / \mathrm{m}$, and secondly - extraction was led here only in one coal seam. The direction of steps throw follows the direction of tectonic faults throw. Summing up - the formation of ground steps in this zone may be connected with fault zone activation as an effect of extraction in one coal seam.

\section{CONCLUDING REMARKS}

In the framework of this work, the analysis of ground steps creation as an effect of underground mining influence combined with tectonic fault activation has been performed.

Especially the influence of certain mining geological factors on the location of steps has been analyzed: the thickness of extracted deposit, spatial distribution of post-mining subsidence and horizontal strain and the course of tectonic fault outcrops. Conducted analyzes allow drawing the following comments and conclusions:

1. Discontinuous deformations in the shape of ground steps pose a significant threat to the objects of urban infrastructure located on the land surface. In the presented case, they ran through the roads surface, causing their damage and the need for costly repairs.

2. The current level of knowledge does not allow predicting the future occurrence of ground steps, as it is in the case of continuous deformations or sinkholes. This makes this type of deformation even more dangerous, the more that securing objects against such damages is very difficult in practice, if not impossible.

3. In the presented case, and others analyzed by authors of this work (Strzałkowski and Ścigała, 2008; Strzałkowski, 2014), a sufficient condition for ground step forming is to conduct an unilateral longwall mining operation in the vicinity of fault in only one coal seam. So, the occurrence of tectonic fault exposed to extraction influences, should be regarded as basic factor initiating the formation of such type of discontinuous deformation. The number of ground steps formed in the vicinity of fault outcrops increases in case of extraction led in several coal seams to the same border line. Such situation is very common in practice, typically when extraction is led to the border of safety pillar established due to fault presence.

4. Another important factor contributing to formation of ground steps is a high level of tensile horizontal strain, acting in the perpendicular direction to the course of deformation. In the presented case, values of $\varepsilon_{\max }$ reached the level of $(+6.0 \div+9.0) \mathrm{mm} / \mathrm{m}$.

5. On the basis of presented results, in the case of planned high-intensity extraction, especially in tectonically disturbed rock mass, authors suggest new attitude to predictions of linear type discontinuous deformation by supplementing conventional forecast with two addition documents:

- the map of total thickness of extracted deposit (an example is presented in Figure 5).

- the map of predicted distribution of principal horizontal strain directions (an example is presented in Figure 6)

With such documents, it is possible to determine the probable directions of linear - type discontinuous deformations.

\section{REFERENCES}

Chudek, M., Janusz, W. and Zych J.: 1988, The study concerning recognition of creation and prediction of discontinuous deformations under influence of underground mining. Zeszyty Naukowe Politechniki Śląskiej, Górnictwo, nr. 141, Gliwice, 161 pp., (in Polish).

Kaizong, X., Congxin, C., Hua, F., Yucong, P. and Yangyang D.: 2016, Mining-induced ground deformation in tectonic stress metal mines: A case study. Engineering Geology, 210, 212-230. DOI: $10.1016 /$ j.enggeo.2016.06.018

Knothe, St.: 1953, The equation of the subsidence trough asymptotic profile. Archives of Mining and Metallurgy, 1, Kraków, 111-127, (in Polish).

Kotyrba, A. and Kowalski, A.: 2009, Linear discontinuous deformation of A4 highway within mining area „Halemba”. Mineral Resource Mangement, 25, 3, Kraków, 303-317.

Kratzsch, H.: 1983, Mining Subsidence Engineering. Springer-Verlag, Berlin, Heidelberg, New York, 543 pp.

Li, X., Wang, S.-J., T.Y. Liu, T.Y. and Ma, F.S.: 2004, Engineering geology, ground surface movement and fissures induced by underground mining in the Jinchuan Nickel Mine. Engineering Geology, 76, 1-2, 93-107. DOI: 10.1016/j.enggeo.2004.06.008

Malinowska, A.A. and Hejmanowski, R.: 2016, The impact of deep underground coal mining on Earth fissure occurrence. Acta Geodyn. Geomater., 13, 4 (184), 321-330. DOI: 10.13168/AGG.2016.0014

Peng, S.: 2008, Coal mine ground control. 3rd ed., Morgantown, West Virginia University, $750 \mathrm{pp}$.

Ścigała, R.: 2008, Computer aided prediction of rock mass and land surface deformation caused by underground extraction. Wydawnictwo Politechniki Śląskiej, Gliwice, 127 pp.

Strzałkowski, P. and Ścigała, R.: 2008, Discontinuous deformations of linear type - the analysis of their creation in present conditions of underground mining. XIII International Symposium GEOTECHNICS 2008, Conference Proceedings, 425-437, (in Polish).

Strzałkowski, P.: 2010, Overview of mining areas protection. Wydawnictwo Politechniki Śląskiej, Gliwice, 192 pp., (in Polish).

Strzałkowski, P.: 2014, Discontinuous deformations as a result of horizontal deformations. Exploration Geophysics, Remote Sensing and Environment. EGRSE Journal, 2, 18-24.

Woo, K., Eberhardt, E., Elmo, D. and Stead, D.: 2013, Empirical investigation and characterization of surface subsidence related to block cave mining. International Journal of Rock Mechanics \& Mining Science, 61, 31-42.

DOI: 10.1016/i.iirmms.2013.01.015 


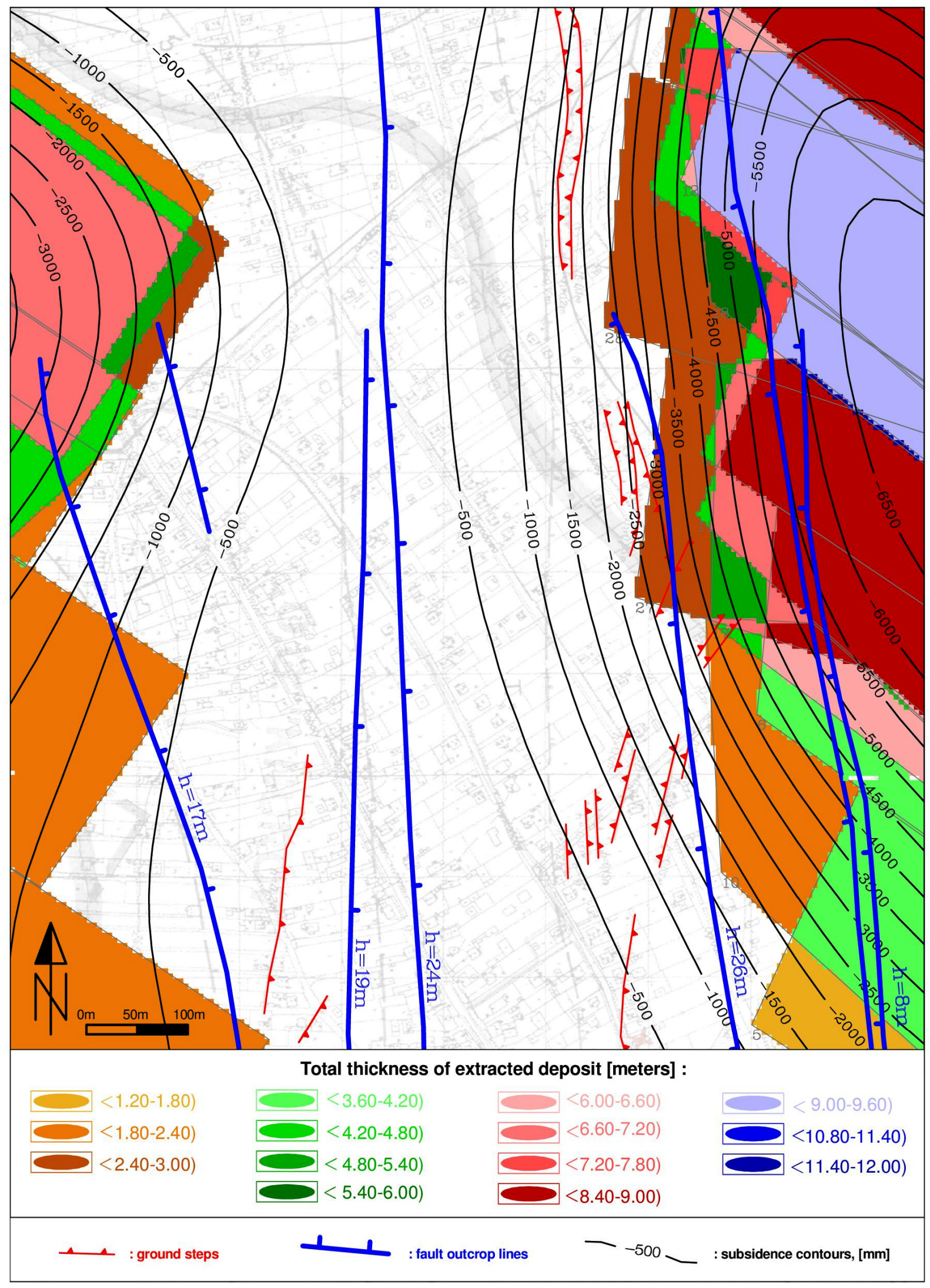

Fig. 5 The map of total extracted deposit thickness with subsidence contour lines. 